Revista Eletrônica de Direito Processual - REDP.

Rio de Janeiro. Ano 10. Volume 17. Número 2. Julho a Dezembro de 2016

Periódico Semestral da Pós-Graduação Stricto Sensu em Direito Processual da UERJ

Patrono: José Carlos Barbosa Moreira. ISSN 1982-7636. pp. 515-530

www.redp.uerj.br

\title{
O ÔNUS DA PROVA NO PROCESSO CONSTITUCIONAL SOB A ÉGIDE DO ESTADO DEMOCRÁTICO DE DIREITO ${ }^{1}$
}

\section{BURDEN OF PROOF IN CONSTITUTIONAL PROCESS UNDER CONSIDERATION OF DEMOCRATIC STATE}

Patrícia Mendanha Dias

Pós-graduanda em Direito Processual pela Pontifícia Universidade Católica de Minas Gerais. Advogada no Departamento de Direito Ambiental do escritório William Freire Advogados Associados. Belo Horizonte/MG. patriciamendanhadias@gmail.com

RESUMO: Sob a égide do Estado Democrático de Direito, o contraditório afigura-se como premissa fundamental do processo constitucionalizado. Nessa ótica, o contraditório, mais que simples direito da parte em exercer seu direito de defesa, deve ser visto como forma de compartipação no processo, permitindo-se às partes a produção probatória como influência efetiva no acertamento do direito. Destarte, deverão ser refutadas as tentativas de mitigação do direito ao contraditório na fase probatória e que imponha à parte a necessidade de produção de prova impossível ou de difícil realização, sob pena de ofensa ao processo entendido no arcabouço normativo hodierno.

PALAVRAS-CHAVE: ônus da prova; inversão; distribuição dinâmica do ônus da prova; processo constitucional; processo no Estado Democrático de Direito.

ABSTRACT: Under the aegis of the democratic rule of law, the contradictory it appears as a fundamental premise of constitutionalised process. In this view, the contradictory, more than just right party to exercise its right of defense, it should be seen as a form of compartipação in the process, allowing the parties to the probative production as an effective influence on acertamento right. Thus, it should be disproved the right mitigation attempts contradictory in the evidentiary phase and imposing aside the need to produce proof

\footnotetext{
${ }^{1}$ Artigo recebido em 19/10/2016 e a aprovado em 28/11/2016.
} 
Revista Eletrônica de Direito Processual - REDP.

Rio de Janeiro. Ano 10. Volume 17. Número 2. Julho a Dezembro de 2016

Periódico Semestral da Pós-Graduação Stricto Sensu em Direito Processual da UERJ

Patrono: José Carlos Barbosa Moreira. ISSN 1982-7636. pp. 515-530

www.redp.uerj.br

impossible or difficult to perform, under penalty of offending the process understood in the modern normative framework.

KEYWORDS: burden of proof; inversion; dynamic distribution of the burden of proof; constitutional process; process in a democratic state

SUMÁRIO: 1. Introdução - 2. O processo na construção do Estado Democrático de Direito: a garantia ao contraditório e da produção probatória como intrínsecos à noção de processo constitucional - 3. O Direito Probatório como garantia de influência nos pronunciamentos judiciais do processo constitucionalizado - 4. A inversão do ônus da prova: uma análise sob a égide do processo constitucionalizado: 4.1 A inversão do ônus da prova como regra de instrução: impossibilidade de concepção da inversão do ônus da prova como regra de julgamento no processo constitucional - 5. A distribuição dinâmica do ônus da prova encampada pelo Código de Processo Civil de 2015 - 6. A (in)possibilidade de atribuir o ônus probatório àquele que não possui condições de provar o fato - 7. Conclusão.

\section{INTRODUÇÃO}

A inclusão do contraditório como viga mestre do processo foi concebida, pela primeira vez, por Fazzalari. O processualista italiano afirmou que processo não se define pela mera sequência, direção ou finalidade dos atos praticados pelas partes ou pelo juiz, mas pela presença do atendimento do direito ao contraditório entre as partes, em simétrica paridade.

Posteriormente, com os estudos empreendidos por José Alfredo de Oliveira Baracho, Hector Fix-Zamudio e Ítalo Andolina e a concepção da teoria constitucionalista do processo, o devido processo passou a ser entendido sob a égide dos princípios da reserva legal, da ampla defesa, isonomia e contraditório.

A partir de então, passou a ser inadmissível a exercício de processo desvinculado da garantia ao contraditório. 
Revista Eletrônica de Direito Processual - REDP.

Rio de Janeiro. Ano 10. Volume 17. Número 2. Julho a Dezembro de 2016

Periódico Semestral da Pós-Graduação Stricto Sensu em Direito Processual da UERJ

Patrono: José Carlos Barbosa Moreira. ISSN 1982-7636. pp. 515-530

www.redp.uerj.br

Ocorre que o contraditório, mais que o direito da parte em provar os fatos constitutivos de seu direito, também deve ser entendido como a necessidade do autor provar os fatos suscitados em seu pleito para que sua pretensão seja atendida.

Perpassa, portanto, pelo direito do Réu em não ter que provar fatos suscitados unicamente pela parte autora e que fundamentariam a pretensão autoral, mas que a produção da prova é de difícil ou impossível realização, como ocorre com as denominadas "provas diabólicas".

Esta ideia de que o contraditório também deve ser entendido como o direito do Réu de não ter que produzir prova impossível dos fatos alegados em seu desfavor surge notadamente após a aplicável indiscriminada da inversão do ônus da prova em demandas de natureza coletiva, nas quais o Julgador - sem se atentar para as peculiaridades do caso concreto -, confere ao Réu a árdua missão de produzir provas de difícil ou impossível realização.

A inversão indiscriminada, todavia, não pode ser aceita à luz do contraditório como garantia de influência e comparticipação e não se afigura legítima sob a noção do processo constitucionalizado, em que as partes deverão ter paridade de tratamento.

\section{O PROCESSO NA CONSTRUÇÃO dO ESTAdO DEMOCRÁtiCO DE DIREITO: A GARANTIA AO CONTRADITÓRIO E DA PRODUÇÃO PROBATÓRIA COMO INTRÍNSECOS À NOÇÃo DE PROCESSO CONSTITUCIONAL}

O devido processo, não mais entendido como instrumento, mas como instituição, não pode ser mitigado com o suposto intuito de garantir o direito material. Após a superação das teorias do processo como contrato, quase-contrato, a própria teoria de Fazzalari e o advento das teorias constitucional e neoinstitucionalista de processo, o processo tornou-se a principal forma de garantia de direitos e garantias fundamentais.

Qualquer forma de mitigar o devido processo - e, por consectário, os princípios a ele inerentes -, mostra-se como ofensa ao Estado Democrático de Direito que fundamenta as relações levadas ao Poder Judiciário.

Ronaldo Bretas e outros lecionam sobre os pressupostos de existência e desenvolvimento do Estado sob a égide da teoria constitucionalista de processo: 
Rio de Janeiro. Ano 10. Volume 17. Número 2. Julho a Dezembro de 2016

Periódico Semestral da Pós-Graduação Stricto Sensu em Direito Processual da UERJ

Patrono: José Carlos Barbosa Moreira. ISSN 1982-7636. pp. 515-530

www.redp.uerj.br

"O Estado só pode agir, se e quando chamado a exercer a função jurisdicional, dentro de uma estrutura metodológica construída normativamente (devido processo legal), de modo a garantir adequada participação dos destinatários na formação de seu ato decisória imperativo. Com essa metodologia, afasta-se qualquer subjetivismo ou ideologia do agente público decisor (juiz), investido pelo Estado do poder de julgar, sem espaço para a discricionariedade ou a utilização de hermenêutica canhestra fundada no prudente ou livre arbítrio do julgador ou prudente critério do juiz, incompatível com os postulados do Estado Democrático de Direito, como, ao contrário, até hoje e infelizmente, alguns doutrinadores supõe a apregoam e outras tantas decisões jurisdicionais consagram em seus fundamentos."2

E complementam:

“A esse desiderato, está o processo planejamento ajustado à referida estrutura normativa (devido processo legal) como procedimento que se realiza em contraditório entre as partes, por exigência do devido processo constitucional, sem exceção de espécie alguma. É o contraditório que viabiliza a participação simetricamente igualitária das partes destinatárias do pronunciamento jurisdicional decisório final." 3

Justamente com espeque nesta ideia de que o processo constitucional não pode ser analisado se desvinculado da garantia ao contraditório e a efetiva garantia de participação isonômica das partes no procedimento, é que surge a necessidade de estudo da produção probatória como forma de concretização dos princípios do processo constitucionalizado.

${ }^{2}$ CARVALHO DIAS. Ronaldo Brêtas. BRETAS. Carlos Henrique. BRETAS. Suzana Oliveira Marques. DIAS. Renato José Barbosa. BRETAS. Yvonne Mól. Estudo Sistemática do NCPC (com as alterações introduzidas pela Lei no 13.256, de 4/2/2016). Belo Horizonte: Editora D’Plácido, 2016.

${ }^{3}$ Idem, ibidem. 
Revista Eletrônica de Direito Processual - REDP.

Rio de Janeiro. Ano 10. Volume 17. Número 2. Julho a Dezembro de 2016

Periódico Semestral da Pós-Graduação Stricto Sensu em Direito Processual da UERJ

Patrono: José Carlos Barbosa Moreira. ISSN 1982-7636. pp. 515-530

www.redp.uerj.br

Não se pode olvidar que é na produção probatória que os sujeitos processuais devem ter a oportunidade de exercer o exercício pleno do contraditório, consistente no dizer, contradizer ou se abster de dizer quando o fato constitutivo do direito tiver que ser produzido pela parte contrária.

No exercício do contraditório como garantia de influência não se admitem como externalização dos pronunciamentos das partes a simples manifestação no iter procedimental, havendo-se a necessidade de garantir às partes todas as formas de defesa ao direito vindicado, incluindo-se o conhecimento prévio dos fatos que substanciam a lide (delimitação e os sujeitos processuais responsáveis pelo ônus de provar

É impossível, na égide do Estado Democrático de Direito, pensar em direito probatório e, por consectário, na fase instrutória do processo civil, sem nos remetermos aos postulados do processo constitucional e no contraditório como direito de participação isonômica e garantia de influência.

\section{O DIREITO PROBATÓRIO COMO GARANTIA DE INFLUENCIA NOS PRONUNCIAMENTOS JUDICIAIS DO PROCESSO CONSTITUCIONALIZADO}

Sendo o direito probatório forma de garantia do direito ao contraditório, a produção de prova em processos judiciais deve ser entendida como garantia efetiva de influência nos pronunciamentos judiciais, consistente na possibilidade de dizer e contradizer em um interprocedimental marcado pela paridade de partes.

André Cordeiro Leal esclarece que o Código de Processo Civil brasileiro aderiu ao sistema probatório da persuasão racional que vincula a formação do convencimento do juiz às provas dos autos ${ }^{4}$.

O Autor afirma ainda que o julgador deve conferir à sentença uma estrutura silogística, conforme anota Ovídio Baptista da Silva, não obstante a prolação das decisões não se encontre adstrita a um procedimento silogístico.

Ronaldo Bretas e outros dissertam que o devido processo legal deve direcionar um procedimento que possa concretizar o direito à produção da prova, como coextensão da garantia da ampla defesa, dentro de uma estrutura técnica normativa em contraditório, a fim

\footnotetext{
${ }^{4}$ CORDEIRO LEGAL. André. O contraditório e a Fundamentação das Decisões no Direito Processual Democrático. Belo Horizonte: Mandamentos, 2002.
} 
Revista Eletrônica de Direito Processual - REDP.

Rio de Janeiro. Ano 10. Volume 17. Número 2. Julho a Dezembro de 2016

Periódico Semestral da Pós-Graduação Stricto Sensu em Direito Processual da UERJ

Patrono: José Carlos Barbosa Moreira. ISSN 1982-7636. pp. 515-530

www.redp.uerj.br

de permitir a cognição dos fatos narrados ou enunciados pelas partes em seus arrazoados e a valoração das provas por elas apresentadas na comprovação de suas narrativas, visando a obter um pronunciamento estatal decisório favorável às partes ${ }^{5}$.

Rosemiro Pereira Leal, ao entender a prova como forma de fixação de fatos do processo, estabelece que a atividade probatória deve ser regida pelos princípios da indiciaridade, da ideação e da formalização. Em suas palavras:

"A prova, portanto, como instituto jurídico, para cumprir sua finalidade de "fixação dos fatos do processo", enuncia-se pelos conteúdos lógicos de aproximação dos seguintes princípios: a) indiciariedade (caracterizada pelos elementos integrativos da realidade objetivada no espaço); b) ideação (exercício intelectivo da apreensão dos elementos pelos meios do pender no tempo); c) formalização (significa a instrumentação da realidade pensada pela forma legal)." 6

Em complemento à teoria da prova empreendida pelos autores clássicos, Camilla Paolinelli e Luciano Vieira esclarecem a função e finalidade da prova e ônus como garantia da ampla argumentação das partes e freio à discricionariedade e subjetivismo do Juiz:

"A prova e ônus, assim, projetam-se como garantias da ampla argumentação das partes, vinculativos do pronunciamento estatal. Permitem aos sujeitos processuais a reconstrução dos fatos narrados de forma completa, conferindo a estes o direito de participar ativamente da confecção do provimento. O exercício amplo da prova (ou a opção pelo ônus) afasta a abertura para a discricionariedade e

${ }^{5}$ CARVALHO DIAS. Ronaldo Brêtas. BRETAS. Carlos Henrique. BRETAS. Suzana Oliveira Marques. DIAS.Renato José Barbosa. BRETAS. Yvonne Mól. Estudo Sistemática do NCPC (com as alterações introduzidas pela Lei n⿳ 13.256, de 4/2/2016). Belo Horizonte: Editora D'Plácido, 2016.

${ }^{6}$ LEAL. Rosemiro Pereira. Teoria geral do processo: primeiros estudos. 12 ed. Rio de Janeiro: Forense, 2014. 
Revista Eletrônica de Direito Processual - REDP.

Rio de Janeiro. Ano 10. Volume 17. Número 2. Julho a Dezembro de 2016

Periódico Semestral da Pós-Graduação Stricto Sensu em Direito Processual da UERJ

Patrono: José Carlos Barbosa Moreira. ISSN 1982-7636. pp. 515-530

www.redp.uerj.br

subjetivismo do juízo, estimulando o controle e a efetiva influência

nas decisões que afetarão as partes."7

É que, conforme nos ensina Ronaldo Bretas, a ideia de ônus da prova concebida por Elio Fazzalari deve ser entendida como situação de prejuízo assumida pela parte, como consequência da ausência ou da abstenção da prática de algum ato no processo e, portanto, “como ato processual que a parte pode cumprir ou não, mas cuja ausência ou omissão se resolve em seu próprio prejuízo”.

Com base nestes postulados, tem-se que o ônus da prova pode ser conceituado como faculdade do sujeito processual em produzir prova favorável ou contrária ao fato substrato da lide, cuja opção pelo não exercício poderá acarretar prejuízo àquele que se desincumbiu de provar.

O que a norma processual e os doutrinadores preveem como ônus probatório é justamente o livre arbítrio da parte para requerer e produzir as provas que entender necessárias para dizer ou contradizer os fatos postos em juízo e que, juntamente com o arcabouço jurídico, formaram o conjunto de fatos e argumentos utilizados pelo Julgador para a efetivação da jurisdição.

Destarte, se o não exercício da faculdade probante pode acarretar à parte que lhe incumbia o prejuízo de se não se confirmarem os fatos alegados no processo, a atribuição do ônus probatório deve ser analisada sob a égide das premissas que regem o processo constitucional.

Isto quer dizer que, estará em desacordo com os postulados do processo sob a égide do Estado Democrático de Direito, todas as atribuições dos ônus probatórios que tornarem impossível ou de extrema dificuldade o exercício da faculdade probatória.

Este postulado decorre justamente no entendimento de que a produção probatória consiste em uma das formas mais legítimas de exercício pleno do contraditório e da ampla defesa e que o entrave à sua realização representará ofensa às garantias constitucionalmente positivadas.

\footnotetext{
${ }^{7}$ PAOLINELLI. Camilla Mattos. VIEIRA. Luciano Henrik Silveira. Da íntima relação entre ônus da prova e valoração como mecanismo de controle do conteúdo do pronunciamento jurisdicional in CARVALHO DIAS. SOARES. Carlos Henrique. RÚA. Monica Maria Bustamente. GIRALDO. Liliana Damaris Pabón. ANDRADE. Francisco Rabelo Dourado de. Direito Probatório: temas atuais. Belo Horizonte: Editora D’Plácido, 2016. P. 219.
} 


\section{A INVERSÃo DO ÔNUS DA PROVA: UMA ANÁllSE SOB A ÉGIDE DO PROCESSO CONSTITUCIONALIZADO}

Segundo determinava o revogado art. 333 do Código de Processo Civil de 1973, o ônus da prova incumbia ao autor, quanto ao fato constitutivo de seu direito e ao réu, quanto à existência de fato impeditivo, modificativo ou extintivo do direito do autor.

Com o advento do Código de Defesa do Consumidor (Lei $n^{\circ}$ 8.078/1990) e a consagração do microssistema jurídico autônomo com o reconhecimento da vulnerabilidade do consumidor no mercado de consumo e a necessidade de ações governamentais no sentido de proteger efetivamente o consumidor, o art. $6^{\circ}$, VIII da Codificação estabeleceu como direito básico do consumidor a facilitação da defesa de seus direitos, inclusive com a inversão do ônus da prova, a seu favor, no processo civil quando, a critério do juiz, for verossímel a alegação ou quando ele for hipossuficiente, segundo as regras ordinárias de experiências.

Após essa concepção, a regra até então praticada da necessidade da parte autora de provar o fato constitutivo de seu direito foi mitigada em casos nos quais a controvérsia fosse de natureza consumeirista.

Em uma primeira análise, partindo-se da ideia de que o processo constitucional deve garantir a paridade de tratamento às partes e a influência efetiva nos pronunciamentos jurisidicionais, a inversão do ônus da prova no Código de Defesa do Consumidor permitiria com que à parte que não teria condições de provar o fato constitutivo de seu direito não fosse prejudicada.

Ao contrário disto, verificando-se que a parte ré (fornecedor, nos termos do CDC) teria melhores condições de comprovar o fato negativo, justifica-se a inversão do ônus da prova, desde que mediante decisão justificada proferida na fase instrutória.

Ocorre que, diversamente das garantias pretendidas com o advento do CDC, a regra de inversão do ônus da prova passou a ser aplicado de forma indiscriminada nos processos civis.

A garantia, inicialmente pensada como forma de oportunidade paritária de acesso ao contraditório, passou a ser unicamente garantida à parte tida como "hipossuficiente", ferindo os direitos inerentes ao processo da parte contrária. 
Revista Eletrônica de Direito Processual - REDP.

Rio de Janeiro. Ano 10. Volume 17. Número 2. Julho a Dezembro de 2016

Periódico Semestral da Pós-Graduação Stricto Sensu em Direito Processual da UERJ

Patrono: José Carlos Barbosa Moreira. ISSN 1982-7636. pp. 515-530

www.redp.uerj.br

Isto porque, o inicial intento de garantir a proteção do consumidor (e as garantidas

previstas no $\mathrm{CDC}$ ) passou a consistir em aplicação indiscriminada da regra de "inversão do ônus da prova" em inobservância das as regras inerentes ao processo constitucional.

Diferente do que seria a conduta processual adequada, de forma automática e sem análise do caso concreto, os Juízos passaram a conferir ao Réu o ônus de provar em toda e qualquer demanda consumeirista e, posteriormente, para as demandas que envolvessem direitos de natureza difusa.

Desta forma, a distribuição do ônus probatório poderá consistir em flagrante ofensa ao contraditório da parte que, por não ter condições de contradizer as questões levantas pelo autor da demanda, será prejudicado com o provável julgamento de procedência.

\subsection{A inversão do ônus da prova como regra de instrução: impossibilidade de concepção da inversão do ônus da prova como regra de julgamento no processo constitucional}

Com o advento da possibilidade de inversão do ônus da prova como forma de facilitação da defesa do consumidor, a jurisprudência passou a analisar se a inversão do ônus da prova seria regra de instrução ou poderia ser apreciada somente quando do julgamento da demanda.

A análise jurisprudencial, portanto, passou a analisar se o Julgador, na fase instrutória do processo, estaria obrigado a definir os ónus probatórios das partes na demanda ou se, caso não o fizesse, poderia julgar a ação em desfavor de uma das partes por não ter comprovado o fato constitutivo de seu direito.

O Superior Tribunal de Justiça, até o ano de 2010, não possuía tese formada sobre o assunto.

Verifica-se, por exemplo, no julgamento do RESP 1125621/MG, de relatoria da Min. Nancy Andrighi, de 19/08/2010 ${ }^{8}$, a constatação de que a jurisprudência do STJ não havia se pacificada quanto à possibilidade de o juízo inverter o ônus da prova no momento de proferir a sentença numa ação que discuta relação de consumo. A Ministra afirma que inexiste surpresa na inversão do ônus da prova apenas no julgamento da ação consumeirista, vista

\footnotetext{
${ }^{8}$ STJ. REsp 1125621/MG, Rel. Ministra NANCY ANDRIGHI, TERCEIRA TURMA, julgado em 19/08/2010,
} DJe 07/02/2011. 
Revista Eletrônica de Direito Processual - REDP.

Rio de Janeiro. Ano 10. Volume 17. Número 2. Julho a Dezembro de 2016

Periódico Semestral da Pós-Graduação Stricto Sensu em Direito Processual da UERJ

Patrono: José Carlos Barbosa Moreira. ISSN 1982-7636. pp. 515-530

www.redp.uerj.br

que esta possibilidade está presente desde o ajuizamento da ação e nenhuma das partes pode alegar desconhecimento quanto à sua existência.

O entendimento da Corte foi se modificando a partir de 2011, notadamente após a prolação do julgamento do RESP 802832/MG de relatoria do Min. Paulo de Tarso Sanseverino, de 13/04/2011.

Neste julgamento, o Ministro destacou que a distribuição do ônus da prova, além de consistir regra de julgamento dirigida ao juiz (aspecto objetivo), apresenta-se também como norma de conduta para as partes, pautando, conforme o ônus atribuído a cada um deles, o seu comportamento processual (aspecto subjetivo). Assim, se o modo como a distribuição do ônus da prova influi no comportamento processual das partes, não pode a inversão ocorrer quando do julgamento da causa pelo juiz. ${ }^{9}$

Posteriormente a este julgado, a jurisprudência do STJ firmou-se no sentido de que a inversão do ônus da prova prevista no art. $6^{\circ}$, VIII, do CDC, é regra de instrução e não regra de julgamento, sendo que a decisão que a determinar deve - preferencialmente - ocorrer durante o saneamento do processo ou - quando proferida em momento posterior - garantir a parte a quem incumbia esse ônus a oportunidade de apresentar suas provas. ${ }^{10}$

Carlos Henrique Soares e Ronaldo Brêtas Carvalho Dias consignam o entendimento de que o melhor momento para a determinação da inversão seria mesmo no despacho saneador, melhor dizendo, quando proferida a decisão interlocutória que declara saneado o processo, pois é neste momento que se toma o rumo procedimental da instrução processual. ${ }^{11}$

Também nesse sentido, Fredie Didier Jr assevera que não é possível a inversão judicial do ônus da prova feita na sentença, uma vez que o processo cooperativo exige que a modificação do ônus da prova respeite a necessidade de prévia informação às partes de novos encargos probatórios e permitir a atuação da parte para desimcumbir-se do novo ônus a ela imposto. $^{12}$

\footnotetext{
${ }^{9}$ STJ. REsp 802.832/MG, Rel. Ministro PAULO DE TARSO SANSEVERINO, SEGUNDA SEÇÃO, julgado em 13/04/2011, DJe 21/09/2011.

${ }^{10}$ STJ. AgRg no REsp 1450473/SC, Rel. Ministro MAURO CAMPBELL MARQUES, SEGUNDA TURMA, julgado em 23/09/2014, DJe 30/09/2014.

${ }^{11}$ SOARES. Carlos Henrique. CARVALHO DIAS. Ronaldo Bretas. Manual Elementar de Processo Civil. 3 ed. Belo Horizonte: Del Rey, 2014. p. 491.

${ }^{12}$ DIDIER JR. Fredie. Curso de Direito Processual: teoria da prova, direito probatório, ações probatórias, decisão, precedente, coisa julgada e antecipação dos efeitos da tutela. 10 ed. Salvador: Jus Podivm, 2015. p. 125
} 
Revista Eletrônica de Direito Processual - REDP.

Rio de Janeiro. Ano 10. Volume 17. Número 2. Julho a Dezembro de 2016

Periódico Semestral da Pós-Graduação Stricto Sensu em Direito Processual da UERJ

Patrono: José Carlos Barbosa Moreira. ISSN 1982-7636. pp. 515-530

www.redp.uerj.br

Deveras, os entendimentos jurisprudencial e doutrinário não se afastam da visão de processo consentânea com premissas constitucionais democráticas. Não há dúvidas de que a inversão do ônus da prova poderá influir no comportamento das partes na fase probatória de modo que somente a decisão que fixar os pontos controvertidos e estabelecer de forma definitiva o dever dos sujeitos processuais na produção do conjunto de provas colocará ordem ao processo e possibilitará o exercício pleno do contraditório e ampla defesa.

Por outro lado, caso a inversão do ônus da prova somente venha ocorrer no julgamento e, portanto, quando já finalizada a fase instrutória do processo, não haverá mais possibilidade da parte exercer seu direito ao contraditório e produzir as provas a seu favor.

Nesse sentido, o processo constitucionalizado intrinsicamente vinculado aos paradigmas democráticos de publicidade, transparência, boa-fé, comparticipação e garantia ao contraditório não se amolda às figuras que, de qualquer modo, possam consistir em entrave à busca da verdade real e ao entendimento do processo como forma legítima de garantia de direitos.

\section{A DISTRIBUIÇÃO DINÂMICA DO ÔNUS DA PROVA ENCAMPADA PELO CÓDIGO DE PROCESSO CIVIL DE 2015}

Concebendo a teoria inserta no Código de Defesa do Consumidor, o Código de Processo Civil de 2015, após repetir a redação do antigo art. 333 no novel art. 373, incluiu o parágrafo único no dispositivo para determinar que nos casos previstos em lei ou diante de peculiaridades da causa relacionadas à impossibilidade ou excessiva dificuldade de cumprir o encargo nos termos do caput ou à maior facilidade de obtenção da prova do fato contrário, poderá o juiz atribuir o ônus da prova de modo diverso, desde que o faça por decisão fundamentada, caso em que deverá dar à parte oportunidade de se desincumbir do ônus que lhe foi atribuído.

A ideia encampada no CPC/15, portanto, aprimorou a técnica da inversão do ônus da prova para a concepção de distribuição dinâmica do ônus da prova.

Isto é, diante de peculiaridades do caso concreto, o juiz pode atribuir a atividade probatória para aquele que tiver em melhores condições de provar o fato questionado.

A nova regra deverá ser aplicada em todas as demandas que possuam especificidades, inclusive as decorrentes das relações de consumo. Diante disto, o Juiz não poderá mais - 
Revista Eletrônica de Direito Processual - REDP.

Rio de Janeiro. Ano 10. Volume 17. Número 2. Julho a Dezembro de 2016

Periódico Semestral da Pós-Graduação Stricto Sensu em Direito Processual da UERJ

Patrono: José Carlos Barbosa Moreira. ISSN 1982-7636. pp. 515-530

www.redp.uerj.br

sem justificativa devidamente fundamentada - inverter o ônus da prova em desfavor de uma das partes quando esta não se mostrar capaz de construir provas do fato em questão.

O paradigma vem justamente no sentido de compreender o processo sob o panorama do Estado Democrático de Direito, em que o exercício da prestação jurisdicional deve observar a busca pela efetivação dos direitos em um processo marcado pela paridade de armas, isonomia e garantia ao contraditório.

Com base nestes pressupostos, seria incabível a concepção anterior de, simplesmente, inverter o ônus da prova sem antes a verificação do caso concreto da possibilidade/necessidade da parte contrária produzir a prova constitutiva do direito pleiteado.

Entende-se que, se o exercício do ônus probante está necessariamente vinculado ao contraditório e que o resultado da instrução processual influi diretamente no provimento jurisdicional vindicado, a atribuição das responsabilidades da prova não pode ser singela a ponto de não adentrar nas peculiaridades do caso concreto e na real possibilidade da parte que alega incumbir-se de comprovar suas alegações.

\section{A (IN)POSSIBILIDADE DE ATRIBUIR O ÔNUS PROBATÓRIO ÀQUELE QUE NÃO POSSUI CONDIÇÕES DE PROVAR O FATO}

$\mathrm{Na}$ égide do $\mathrm{CPC} / 73$ cumulado com as disposições do $\mathrm{CDC}$, apesar de não existir requisitos expressos nos quais a inversão do ônus da prova seria possível, entende-se que os preceitos que regem o processo constitucional não deixavam margem para que o julgador proferisse decisão de atribuição do ônus da prova que tornasse impossível ou extremamente dificultosa a defesa da parte.

Isto porque, por tudo o que foi falado, a produção de prova em processos judiciais deve ser entendida como garantia de influência e comparticipação no inter-procedimental marcado pela paridade das partes.

Mais que isto, se já se não era possível a inversão indiscriminada sob a égide do $\mathrm{CPC} / 73$, ainda mais absurdas se tornam as decisões judiciais que, sem justificativa racional, atribuam ao Réu a necessidade de provar fatos de impossível realização.

Sobre o tema, leciona Alexandre de Freitas Câmara que "só se poderá admitir essa redistribuição do ônus da prova se o encargo for, pela decisão judicial, atribuído a quem 
Revista Eletrônica de Direito Processual - REDP.

Rio de Janeiro. Ano 10. Volume 17. Número 2. Julho a Dezembro de 2016

Periódico Semestral da Pós-Graduação Stricto Sensu em Direito Processual da UERJ

Patrono: José Carlos Barbosa Moreira. ISSN 1982-7636. pp. 515-530

www.redp.uerj.br

tenha condições de dele desimcumbir-se não se podendo, com a redistribuição do ônus da prova, gerar uma situação em que a desimcumbência de tal encargo seja impossível ou excessivamente difícil. (art. $373 \$ 2^{\circ}$ )"13

De fato, conforme lição do autor, o CPC/15, especificamente no artigo 373 §2 determina que, a decisão que fixar a distribuição do ônus da prova não poderá gerar situação em que a desincumbência do encargo pela parte seja impossível ou excessivamente difícil.

O ditame legal, consentâneo com os princípios regentes do processo constitucionalizado, pretende evitar justamente a pratica há muito adotado pelo Poder Judiciário e que, por via transversa, mitigava o exercício do contraditório pelo Réu ao lhe impor o ônus de realizar provas impossíveis.

Neste novo contexto, entende-se que deverão ser superadas as decisões comumente proferidas sob a égide do CPC/73 e que, simplesmente, por versaram sobre demandas de natureza consumeirista, determinavam ao Réu a árdua - quando não impossível - missão de comprovar fatos por meio de provas de impossível realização.

Se a análise do processo sob o viés constitucional já impedia com que as decisões na fase instrutória fossem proferidas em desrespeito ao princípio do contraditório e ao entendimento do processo em paridade entre as partes, com muita mais razão se afiguram nulas todas as decisões proferidas após a vigência do CPC/15 que invertam o ônus da prova sem justificativa devidamente motivada.

\section{CONCLUSÃO}

No processo marcado pelo respeito às garantias e princípios básicos, notadamente o contraditório como garantia de influência nos pronunciamentos judiciais, torna-se fundamental a garantia da fase probatória alinhada à possibilidade real da parte em produzir prova capaz de confirmar ou afastar o fato probando.

Mormente com a entrada em vigor do CPC/15 e a concepção da teoria de distribuição dinâmica do ônus da prova, torna-se totalmente desarrazoado à atribuição do dever de provar por meio da realização de provas impossíveis.

\footnotetext{
${ }^{13}$ CÂMARA. Alexandre. O novo processo civil brasileiro. São Paulo: Atlas, 2015. p. 233
} 
Revista Eletrônica de Direito Processual - REDP.

Rio de Janeiro. Ano 10. Volume 17. Número 2. Julho a Dezembro de 2016

Periódico Semestral da Pós-Graduação Stricto Sensu em Direito Processual da UERJ

Patrono: José Carlos Barbosa Moreira. ISSN 1982-7636. pp. 515-530

www.redp.uerj.br

Do mesmo modo, fica finalmente superado o entendimento que vigorou durante

período significativo no Superior Tribunal de Justiça de que a inversão do ônus da prova seria regra de julgamento e não de instrução, uma vez que após a decisão que distribuir o ônus da prova, o juiz deverá oportunizar à parte o direito de se desimcumbir do ônus e, se possível for, produzir a prova determinada pelo Juízo.

A partir do novo paradigma e notadamente com as modificações introduzidas pelo Código de Processo Civil, a produção probatória e a definição dos ônus de provar deve estar consentânea com as peculiaridades do caso concreto e a possibilidade da parte, efetivamente, ter condições de exercer o contraditório como meio de influência e não surpresa.

O contraditório, entendido como o direito da parte de exercer seu direito de defesa em paridade de armas com os demais sujeitos processuais, não pode ser mitigado pelo fato, único e simples, da demanda se tratar, por exemplo, de matéria de natureza consumeirista.

A ampla defesa e todos os meios a ela inerentes não devem ser mitigados sob o argumento do processo objetivar a efetivação do direito material, mormente ao se considerar que o devido processo constitucionalizado no paradigma do Estado Democrático de Direito trata-se de forma legítima de efetivação das garantias estabelecidas na CF/88.

Nesse sentido, mesmo em casos que envolvem demandas cujo plano de fundo há direitos difusos e notadamente após a concepção da distribuição dinâmica do ônus da prova encampado pelo CPC/15, o início da fase probatória deverá ocorrer por decisão devidamente fundamentada em que o Juiz possa definir o ônus das partes da produção das provas necessárias ao deslinde da controvérsia.

Nesta decisão, deverão ser explicitados os motivos pelos quais o Julgador entende que a realização da prova em determinado contexto poderá ser facilitada pela parte que a incumbe e, ainda assim, deverá ser aberta oportunidade à parte para se desimcumbir do ônus.

\section{REFERÊNCIAS BIBLIOGRÁFICAS}

ANDRADE. Francisco Rabelo Dourado. Atividade Probatória na ação de improbidade administrativa: estudos de teoria da prova a partir da processualidade democrática in CARVALHO DIAS. SOARES. Carlos Henrique. RÚA. Monica Maria Bustamente. GIRALDO. Liliana Damaris Pabón. ANDRADE. Francisco Rabelo Dourado de. Direito Probatório: temas atuais. Belo Horizonte: Editora D’Plácido, 2016. 
CÂMARA. Alexandre. O novo processo civil brasileiro. São Paulo: Atlas, 2015.

CARVAlHO DIAS. Ronaldo Brêtas de Carvalho. Processo Constitucional e Estado Democrático de Direito. Belo Horizonte. Del Rey, 2010.

CARVALHO DIAS. Ronaldo Brêtas. BRETAS. Carlos Henrique. BRETAS. Suzana Oliveira Marques. DIAS.Renato José Barbosa. BRETAS. Yvonne Mól. Estudo Sistemática do NCPC (com as alterações introduzidas pela Lei $n^{0}$ 13.256, de 4/2/2016). Belo Horizonte: Editora D’Plácido, 2016.

CORDEIRO LEGAL. André. O contraditório e a Fundamentação das Decisões no Direito Processual Democrático. Belo Horizonte: Mandamentos, 2002.

COUTURE. Eduardo J. Introdução ao estudo do processo civil. 3 ed. Rio de Janeiro, 2004.

DIDIER JR. Fredie. Curso de Direito Processual: teoria da prova, direito probatório, ações probatórias, decisão, precedente, coisa julgada e antecipação dos efeitos da tutela. 10 ed. Salvador: Jus Podivm, 2015. p. 125

LEAL. Rosemiro Pereira. Teoria geral do processo: primeiros estudos. 12 ed. Rio de Janeiro: Forense, 2014.

PAOLINELLI. Camilla Mattos. VIEIRA. Luciano Henrik Silveira. Da íntima relação entre ônus da prova e valoração como mecanismo de controle do conteúdo do pronunciamento jurisdicional in CARVALHO DIAS. SOARES. Carlos Henrique. RÚA. Monica Maria Bustamente. GIRALDO. Liliana Damaris Pabón. ANDRADE. Francisco Rabelo Dourado de. Direito Probatório: temas atuais. Belo Horizonte: Editora D’Plácido, 2016.

SOARES. Carlos Henrique. CARVALHO DIAS. Ronaldo Bretas. Manual Elementar de Processo Civil. 3 ed. Belo Horizonte: Del Rey, 2014. 
Revista Eletrônica de Direito Processual - REDP.

Rio de Janeiro. Ano 10. Volume 17. Número 2. Julho a Dezembro de 2016

Periódico Semestral da Pós-Graduação Stricto Sensu em Direito Processual da UERJ

Patrono: José Carlos Barbosa Moreira. ISSN 1982-7636. pp. 515-530

www.redp.uerj.br

STJ. AgRg no REsp 1450473/SC, Rel. Ministro MAURO CAMPBELL MARQUES,

SEGUNDA TURMA, julgado em 23/09/2014, DJe 30/09/2014.

STJ. REsp 1125621/MG, Rel. Ministra NANCY ANDRIGHI, TERCEIRA TURMA, julgado em 19/08/2010, DJe 07/02/2011.

STJ. REsp 802.832/MG, Rel. Ministro PAULO DE TARSO SANSEVERINO, SEGUNDA SEÇÃO, julgado em 13/04/2011, DJe 21/09/2011. 